\title{
Los debates en torno al ferrocarril en España anteriores a la creación de RENFE: el camino hacia el monopolio de Estado
}

\author{
José Luis MALO GUILLÉN \\ Universidad de Zaragoza \\ jmalo@unizar.es \\ Begoña PÉREZ CALLE \\ Universidad de Zaragoza \\ bperez@unizar.es
}

Received: 01/06/2015

Accepted: 14/06/2016

\begin{abstract}
Resumen
Desde su nacimiento hasta la caída de la dictadura de Primo de Rivera, el ferrocarril se perfiló como una industria doblemente creadora de riqueza, estimulando por un lado la ya existente e impulsando el desarrollo económico por otro. Ante sus peculiaridades técnicas, económicas y de mercado, los distintos gobiernos adoptaron soluciones intervencionistas de mayor o menor grado. Simultáneamente, en su primer desarrollo, se produjo el abandono del paradigma clásico basado en la libre competencia, lo que derivó en la conversión del ferrocarril en foco de la retórica anti-competencia y de la práctica intervencionista.

En este trabajo realizamos un seguimiento del nacimiento y desarrollo del ferrocarril, centrado exclusivamente en la evolución político-económica del sector dentro de la propia evolución histórica, paralela a la vía nacionalista del capitalismo español, y en la descriptiva teórica y práctica del desarrollo del intervencionismo y las restricciones al libre mercado.
\end{abstract}

Palabras clave: ferrocarril, retórica anti-competencia, monopolio, intervencionismo de Estado

\begin{abstract}
From its birth until the fall of Primo de Rivera dictatorship, the railroad emerged as an industry creating wealth doubly: by one hand stimulating the existing wealth and impelling economic development on the other. Because of their technical, economic and market peculiarities, the different governments adopted interventionist solutions in greater or lesser degree. Simultaneously, in its early development, the classical paradigm based on free competition was abandoned, which led to the conversion of railroad in a rhetorical focus of anti-competitive and interventionist practice.

In this paper we track the birth and development of the railroad, focused exclusively on political and economic evolution of this sector within the historical evolution -parallel to the nationalist path of Spanish capitalism- and in the descriptive theory and practice of development of interventionism and restrictions to free market.
\end{abstract}

Keywords: railroad, anti-competition rhetoric, monopoly, State interventionism

JEL Classification: B15, B25, N7

\section{Introducción}

El intervencionismo español en el ferrocarril, tras un pequeñísimo paréntesis liberal, fue continuo. El sector se materializó como un elemento básico en la gestación y desarrollo del nacionalismo económico, especialmente a comienzos del siglo XX, cuando el regeneracionismo económico pone en marcha un proceso selector de sectores clave en los que basar la recuperación nacional, cobrando un protagonismo especial el ferrocarril.

Dos fueron los elementos intervencionistas básicos en la teoría y práctica de la explotación industrial: la extorsión a la libre maximización del beneficio tanto vía restricciones en el empleo de recursos (como es el caso del factor carbón) como la fijación de precios (intervencionismo en tarifas). Para ilustrar todos estos argumentos se ahondará en el debate y las posiciones del pensamiento económico en torno al ferrocarril que se publicitaron en el contexto de la situación económica y financiera general a lo largo de esta época, estableciendo, a través de ello, una 
clasificación de los argumentos intervencionistas por un lado y de las grandes propuestas para la intervención por otro, permaneciendo como elemento común en la gran mayoría de los argumentos ferroviarios la retórica anti-competencia y la defensa del ideal a perseguir: completar la cadena corporativismo-nacionalización-estatificación, lo que perfilará al ferrocarril como un sector en el cual se vio especialmente reflejado el pensamiento económico nacionalista.

Concluiremos así como la política estatificadora en la que aterrizaría el intervencionismo español conviviría con un modelo de empresa alejada del mercado competitivo, sustrato ideal para configurar al joven Ferrocarril como una industria estratégica protagonista de los argumentos españoles anti-competencia, así como un vehículo conductor de la defensa corporativista y del monopolio de Estado.

\section{Ferrocarril y pensamiento económico}

Desde la perspectiva de la teoría económica, el sector del transporte ferroviario no es sólo un simple mercado, como el de cualquier otro bien o servicio existente, sino que cuenta con las suficientes peculiaridades para que desde su origen haya recibido una especial consideración por parte de pensadores, políticos y reformadores. Por un lado, y atendiendo a su demanda, no sólo proporciona un medio privilegiado de facilitar la movilidad de las personas, sino que sobre todo constituye un mecanismo esencial para el comercio de bienes. Este dato, aún más relevante para los tiempos en que no existía el transporte aéreo, supone que el ferrocarril no se limita a prestar servicio a la riqueza preexistente, sino que estimula nueva actividad económica, generando más riqueza en los territorios que atraviesa. Es por ello que constituye una de las infraestructuras que mejor contribuyen al desarrollo económico, fundamentalmente en sus primeras etapas, estructurando mercados cada vez de mayor tamaño y acercando demandantes y oferentes tanto de factores de producción como de bienes de consumo.

En relación con la oferta, la singularidad del sector radica en el contraste extremo entre unos cuantiosísimos costes fijos -los relativos al establecimiento de la red- y unos costes variables prácticamente nulos. De acuerdo con la terminología económica actual, cuando esta relación se da, nos encontramos ante un monopolio natural, dado que la eficiencia económica implica la existencia de una única empresa suministrando el servicio, pues hay que tener en cuenta que los elevadísimos costes de primer asentamiento junto con las economías a escala crecientes, eliminan prácticamente la posibilidad de competencia. Sin embargo, dada la dificultad de sustitución por otros medios de transporte alternativos, tal monopolio otorga a la empresa un poder suficiente para reducir el servicio propiciando la elevación artificial de precios. La obtención de beneficios extraordinarios supone un alejamiento considerable de los niveles óptimos deseables. Si hay más de una empresa, es fácil que se llegue a la cartelización. Ante estos fallos de mercado con sus posibles abusos de poder, los distintos gobiernos han adoptado distintas soluciones, todas ellas encaminadas a proteger al usuario y a potenciar al producto, que enseguida se reveló como altamente necesario para el desarrollo económico de los países.

En el caso de que una empresa ferroviaria pudiese maximizar su beneficio libremente, lo haría creando una función en la cual sus restricciones técnicas vendrían dadas por una producción dependiente de factores fijos y variables; de esta forma intentaría alcanzar la eficiencia económica minimizando los costes generados. Entre los factores variables podemos señalar la relevancia en sus primeras épocas del factor carbón y la imposibilidad en ciertas ocasiones en España de minimizar dichos costes por la obligación de incorporar al proceso productivo los carbones nacionales (más caros y de peor calidad). Con respecto a la fijación de precios, a los que llamaremos tarifas, la intervención estatal impidió, lógicamente, que se formasen los precios derivados del proceso de maximización de beneficios, lo cual a veces convencía a las compañías y a veces no. Así, empresas que eran, de facto, gigantes económicos, no podían crecer más allá de una cierta dimensión, debido a las restricciones a las que estaban sometidas.

Para finalizar este catálogo de las peculiaridades teóricas del sector, no es posible olvidar que la construcción de una red ferroviaria es un proyecto que requiere tiempo y recursos financieros muy considerables, hasta el punto de que puede ocurrir que la inversión necesaria tenga una relevancia de primer orden dentro del mercado financiero nacional, así como en los de materias primas y bienes de producción. De este modo, la construcción constituye en sí misma un negocio que puede ser incluso más rentable que la explotación de los ferrocarriles. Este factor podría 
indudablemente distorsionar la toma de decisiones que posteriormente afectarán al desarrollo y viabilidad del sector.

Los puntos anteriores dan testimonio de que el ferrocarril planteó en ese momento problemas teóricos a la ciencia económica a la vez con una relevancia práctica muy considerable. La emergencia de los grandes grupos industriales de finales del siglo XIX y la captación de mercados cada vez de superior tamaño configuró a al sector ferroviario como uno de los primeros en presentar un reto a los economistas de la época, así como en inspirar una política económica distinta a la que recomendaban los textos tradicionales.

Fundamentalmente, la hipótesis que se va a analizar es que las reflexiones acerca del ferrocarril sufrieron algún tipo de evolución, en consonancia con la evolución teórica general, pero sobre todo con los cambios relativos a la política económica. De este modo, la indicada evolución sería en primer lugar un excelente síntoma del nuevo papel asumido por el Estado en el orden económico, pero a la vez uno de los principales puntales que habrían propiciado la asunción de ese papel más activo por parte del sector público.

\section{Breves referencias al contexto europeo}

Las notables ventajas que supuso la adopción del ferrocarril llevaron a los gobiernos a analizar los costes junto con los beneficios sociales y en muchos países se optó por poner esta industria en manos del Estado. Así, en 1890, cuando el ferrocarril ya había realizado un primer notable desarrollo, encontramos en Europa dieciséis compañías privadas, trece públicas y dos mixtas, siendo el sistema privado el exclusivo en Gran Bretaña y España así como dominante en Francia y Rusia; en Italia encontramos el régimen mixto, en Austria-Hungría domina el público y en Alemania, Bélgica, Suecia y Rumanía podemos decir que el sistema es prácticamente estatal. La evolución a favor de la estatalización fue clara: en 1906 nos encontramos con un claro aumento de los porcentajes de red en manos de los estados europeos (salvo Gran Bretaña, Francia y España).

Dejando a un lado los países donde los ferrocarriles estuvieron desde el principio prácticamente en manos del Estado, podemos observar intervencionismo presente en aquellos en que la industria estaba en manos privadas. Así, en Gran Bretaña, los ferrocarriles se planificaron, construyeron y explotaron por empresas privadas hasta su estatalización en 1947, si bien se observa desde el principio clara intervención en esta explotación privada, figurando la industria ferroviaria como elemento central en muchos debates parlamentarios de los distintos gobiernos, preocupados por el poder monopolístico potencial que podían ejercer las compañías ferroviarias (Gouvirsh, 1999, p. 57), aprobando por ello, ya desde 1839, legislaciones reguladoras del sector.

En Francia, el sistema, aunque inspirado en el británico, presenta un régimen especial de explotación basado en tres principios fundamentales (Merger, 1999, p. 65): concesión de líneas por 99 años, creación de grandes redes favorecidas por un monopolio de explotación y garantía de interés sobre el capital concedido por el Estado. Esta situación fue testigo de muchos debates entre defensores y detractores de las compañías privadas, hasta la estatalización de las redes en 1937.

La política ferroviaria italiana presentó su propia versión en cada Estado antes de la nacionalización: así, el Piamonte escogió una mezcla público-privado y dejó la inversión a las compañías pero sin renunciar a dirigir las líneas a través de concesiones; la Toscana adoptó el sistema privado, atrayendo al capital extranjero; Nápoles tomó el ferrocarril como un juguete del rey, etc. (Giuntini, 1999, p. 84). Así, una de las primeras preocupaciones que adoptó el Estado italiano unificado fue la construcción de una red de infraestructuras, donde las férreas cobrarían especial protagonismo y en 1865 se puso en funcionamiento la nueva organización de esta desordenada industria, reduciéndose las decenas de compañías privadas a menudo en ruinas a unas pocas financieramente más fuertes mientras el Estado, para quien el ferrocarril era un instrumento de fuerte carácter político, construye muchos kilómetros de redes. Permanece así un sistema mixto, hasta llegar a la estatalización de 1905. 


\section{El ferrocarril en España: el marco contra la libertad de mercado}

El Informe Subercase, redactado en 1844 a resultas de la solicitud de la primera línea de gran recorrido Madrid-Cádiz , abogó por regular la libertad de mercado, siendo lo ideal la estatalización que conseguiría que las personas y mercancías puedan transportarse con el mínimo precio posible, dando sitio a la empresa privada únicamente si el Estado decide por cualquier motivo no construir las líneas, y en cualquier caso, con control por parte del Estado con el fin de evitar los abusos que podrían generarse. En el espíritu del informe se apreciaba claramente una postura estatalista anti-competencia (abogando por la eliminación de competidores en la propia industria y también en las sustitutivas), y en segunda instancia la regulación estatal, vía control de tarifas, si los ferrocarriles son explotados por compañías privadas. A pesar de que el informe gozó de prestigio años más tarde, la Real Orden de 1844 se basó en él pero se separó de su espíritu fundamental (Izquierdo, 2000, p. 51), autorizando a la ejecución de los ferrocarriles por cuenta del Estado, sistema en el que las concesiones deberían otorgarse si el peticionario fuese "sujeto de reconocido arraigo", lo que llevó al surgimiento de un movimiento especulativo con respecto a esta industria que desembocó en resultados poco rentables, con lo cual se paralizaron las solicitudes de concesiones en 1846.

La inestabilidad política que acompañó al fin de la década moderada impidió que saliese adelante un proyecto de Bravo Murillo, en 1848, fiel al Informe Subercase; lo mismo ocurre con otro de Seijas Lozano en 1850 y de nuevo se repitieron los hechos en 1853 con el proyecto de Reinoso, de corte estatalista. El caos reinante llevó a una verdadera marabunta de empresas solicitantes de ayudas que desencadenó una lucha parlamentaria por la cual llegaron a cerrarse las cortes, generándose grandes escándalos financieros alrededor del ferrocarril.

El gobierno del Bienio Progresista, de 1854 a 1856, aprueba la Ley General de Ferrocarriles el 3 de junio de 1855, poniendo fin al desorden y gracias a la cual se produce un gran desarrollo ferroviario. Esta Ley conserva los principios del Informe de 1844, permitiendo únicamente la construcción de las líneas a las empresas privadas si el gobierno renuncia a hacerlo y guarda para sí la posibilidad de explotar el ferrocarril aludiendo a los intereses públicos, lo que es un claro argumento intervencionista del nacionalismo español (Fraile, 1998, p. 39).

El mismo argumento aparece implícito en la forma de adjudicación de las líneas de servicio general, que se subvencionaban y adjudicaban por subasta pública, revisándose las tarifas cada cinco años, a lo que añadimos que después de la Ley, el Pliego de condiciones de 1856 contempló la posible estatalización (rescate de las líneas por el Estado), siempre que fuese por causa de utilidad pública, los resultados gracias a esta Ley fueron favorables, abriéndose al público 4.900 kilómetros.

A partir de 1868 observamos un giro hacia el liberalismo a través de las ideas de la Escuela Economista, reflejadas en la legislación ferroviaria. El Decreto de 14 de noviembre de 1868 es una muestra clara, al aludir a que las líneas realmente están monopolizadas por el Estado, siendo dicho monopolio un mal. El ferrocarril dejaba de ser un servicio público para convertirse en una industria particular, siendo la única misión del Estado garantizar la libertad de todos y el Derecho común. Pero ni siquiera en este momento podemos hablar de absoluta libertad, pues el Estado se reserva intervenir en las obras que afectan al dominio público admitiendo expropiaciones y posibilidad de dotar de personalidad jurídica a provincias y municipios.

Durante el reinado de Alfonso XII (1875-1885) y la regencia de María Cristina (1885-1902) la Restauración consolida otra vez el concepto de lo público en amplios sectores económicos, la tendencia general del Estado a la intervención en la vida económica se manifiesta progresivamente. La industria ferroviaria es claro reflejo de ello: en la Ley de Ferrocarriles de 1877, en línea con la de 1855 y en vigor hasta 1918, el intervencionismo es patente en aspectos como el control y vigilancia del servicio y las tarifas, así como la estatalización en la que desembocarán las concesiones una vez pasado el plazo correspondiente.

No triunfaría la estatalización absoluta del ferrocarril, sino que la política ferroviaria tendría que ser un reflejo de la política general: argumentos anti-competencia que esconden una manipulación de la industria ferroviaria por grupos favorecidos, muestra de la realidad de la época. Es un ferrocarril prácticamente cartelizado, un mercado dividido perfectamente de forma que no puedan competir unas compañías con otras. 
Económicamente, en este momento, los ferrocarriles viven una etapa de prosperidad que coincide con el periodo de recuperación económica nacional, pero la crisis agrícola de 1882 se extiende a otros sectores complementarios, lo que provoca un descenso preocupante en la actividad a partir de 1885; con el aumento de las cargas financieras las compañías disminuyen e incluso suprimen a veces los dividendos, la depresión se extiende hasta finales del siglo XIX y principios del XX.

Con la subida al trono de Alfonso XIII se aprecia una pequeña recuperación económica aunque paralelamente, en el sector del ferrocarril, se plantea lo que después, con la guerra de 1914, se llamará el "problema ferroviario": el aumento de las industrias minero-siderúrgica y textil, que en la segunda mitad del siglo XIX cobrarían protagonismo y demandarían un intenso servicio al recién nacido ferrocarril, llevó lógicamente a un aumento del tráfico, generándose así una crisis al no poder responder los ferrocarriles españoles en cuanto a capacidad de transporte a la demanda de viajeros y mercancías .

Mientras tanto, los buenos resultados de las compañías llevan a que la opinión pública reclame una rebaja en tarifas, por lo que el gobierno procede a dicha revisión; revisión que, a pesar de una Orden de 1900 y un Real Decreto de 1905, no puede llevarse a cabo de manera satisfactoria si no es pactando directamente con las empresas ferroviarias, desde la cartelización de facto que subyace a este mercado. A tal efecto se convocó la Conferencia Ferroviaria de 1905.

El pensamiento económico nacionalista, perfectamente divisado desde el Real Decreto de 21 de diciembre de 1900, donde se imponía que solo podrían ser licitadoras de concesiones las compañías españolas, hasta ahora la mayoría constituidas con capital francés, vive su momento de gloria durante la Primera Guerra mundial y el ferrocarril sería un sector sobre el cual especialmente se vería reflejado. A ello hay que añadir un hecho al que normalmente sólo se le ha encontrado trascendencia económica, y sin embargo consideramos que también la tiene política: durante la guerra europea las grandes líneas tenían insuficiente capacidad de transporte, con su correspondiente dificultad en aprovisionamientos. La situación económica ferroviaria pasó en 1915 por una quiebra de abastecimiento de carbón a sus depósitos de la red, así como de materias primas y los gastos de explotación aumentaron más que los ingresos, dejando de ser satisfactorios los resultados (Waiss, 1974, p. 619), agravándose el problema en 1916 con la huelga de personal. En 1917 hubo insuficiencia de productos con evidente escasez de tarifas; además el servicio demandaba inversiones en infraestructura mientras se iba acercando el fin del plazo de disfrute de las concesiones. A pesar de que los gobiernos se sucedían sin tratar el problema de frente, consideramos que se estaba fraguando una nueva tendencia proteccionista, basada en un criterio de prudencia política, materializada en el sector ferroviario y originada por la guerra: el ferrocarril, que ya es una industria necesaria y vital para la riqueza nacional no puede ser sensible a los peligros externos, no puede hacer depender sus niveles de producción de conflictos exteriores ni arriesgarse a quiebras en abastecimientos.

Tras el gobierno de 1917, que no adoptó solución que encauzase el tema, el 21 de marzo de 1918, Alfonso XIII nombra un Gobierno Nacional presidido por Maura y con Cambó en la Cartera de Fomento, de gran preparación en cuanto a ferrocarriles, con ideas nacionalizadoras y estatificadoras. Durante sus ocho meses de ministro de Fomento realizó un proyecto de rescate que no dio tiempo a ser aprobado por las Cortes, porque el gobierno se disolvió. Fue un defensor absoluto del intervencionismo estatal, su concepto de intervencionismo tenía más amplia acepción de lo normal en la época, planteándolo en términos de coordinación y armonía entre el interés privado y el público. Cambó admitió la libertad empresarial en la gestión dentro del intervencionismo, con estatificación de la infraestructura. En opinión de Izquierdo, "su proyecto de rescate y nacionalización, más bien estatificación, de la red de ferrocarriles fue de gran importancia para el futuro de la política ferroviaria [...] constituyó el primer intento serio que se llevaba a la práctica" (Izquierdo, 2000, p. 48).

Tras el asesinato de Eduardo Dato y el traspaso del ministerio de Fomento a Juan de La Cierva, se presenta en 1921 el Proyecto de Ley sobre Transportes, Obras Públicas y Fomento de la Riqueza Nacional, en que por primera vez se define la fórmula del consorcio EstadoCompañías, creando el Consejo Superior de Ferrocarriles. El Gobierno cae en julio sin haberse puesto el proyecto en marcha, entrando otro Gobierno Nacional presidido por Maura, quien 
encargó a Flores de Lemus un plan alternativo que circuló con el título de Ordenación Ferroviaria, armonizando puntos de vista de Cambó y La Cierva y que mantuvo la idea del Consorcio Estado-Compañías. El Proyecto queda en la Comisión del Congreso que lo estudiaba hasta que, tras crear el Consejo Superior Ferroviario en 1922, con un nuevo cambio de gobierno, Argüelles lo hace suyo y lo manda a las Cortes el 4 de abril, pero la inestabilidad política lo deja en el olvido sin aprobar.

En septiembre de 1923, sin haberse aprobado aún el Consejo Superior Ferroviario (en las Cortes desde el 4 de abril), se establece el Directorio Militar tras el Golpe de Estado de Miguel Primo de Rivera. El 12 de julio de 1924, tras informe favorable del Consejo Superior de Ferrocarriles (nuevo nombre del Consejo Superior Ferroviario) se aprobó el Estatuto Ferroviario, que puede definirse de realidad intervencionista y de fin estatalista: el Estado aportaría capital para mejorar las redes, se aceptaría el criterio de que el ferrocarril deberá ser pagado por la tarifa, y se prepararía nueva legislación con las normas correspondientes para un posterior rescate de las líneas por el Estado.

Tas la caída de la dictadura, el gobierno de Dámaso Berenguer redacta un nuevo proyecto que rompe con dicho Estatuto, prorrogando las concesiones, lo que representaba la continuidad de las compañías. También se descartó y se pensó en otro proyecto distinto, apoyado en el Estatuto de 1924, pero otros problemas políticos impidieron que el gobierno continuara, poniendo el tema de los ferrocarriles sin resolver en manos de la Segunda República.

A través de la política ferroviaria hemos comprobado claramente como la tendencia al corporativismo iniciada durante los gobiernos de Maura, cristalizó durante la dictadura de Primo de Rivera. Verdaderamente, con el argumento de que el gobierno partía de un sistema ferroviario desbarajustado, comenzó la intervención, al amparo de la estricta defensa de la necesidad de la gestión pública ferroviaria, y contra el que las compañías clamaron con una argumentación notablemente superficial, iniciándose así un proceso de estatificación de los ferrocarriles.

Los ferrocarriles en España habían tomado ya una dirección única y sin retroceso. Tras la culminación de la política ferroviaria en el corporativismo de la dictadura de Primo de Rivera, esta desembocaría, a pesar de ciertos altibajos de los años 1930, en la estatalización de la posguerra.

\section{El intervencionismo en la maximización de los beneficios}

Una de las vías teóricas de la política intervencionista en el libre mercado es la regulación de las empresas limitando sus objetivos optimizadores, es decir, sus minimizaciones en costes o su fijación del precio de máximo beneficio. La segunda medida ha sido especialmente empleada por las autoridades económicas para evitar los fallos de mercado que conlleva la existencia de monopolios o empresas de competencia imperfecta en general. En España, además, la intervención en minimización de costes también existió, limitando la acción de los empresarios en el mercado de factores, con el entorpecimiento en el alcance de eficiencia que conlleva.

\subsection{El intervencionismo en fijación del precio de máximo beneficio: el asunto de las tarifas}

Si bien el control de los precios o tarifas fue una herramienta básica de intervención en esta industria, ${ }^{1}$ la doctrina tarifaria fue inalterable en España, salvo la excepción de total libertad durante el periodo 1868-1873. Podemos afirmar que el Informe Subercase, con su principio de la tarifa máxima, destinada a garantizar al país frente al objetivo "egoísta" de obtención de beneficios de las compañías privadas (Artola, 1978, p. 391), fue el responsable directo de que el gobierno no pudiese llevar a cabo revisiones tarifarias en el siglo XIX y parte del XX, sólo planteándose rebajas. Aun así, los precios resultantes fueron menores a los de cualquier otro sistema de transporte. Conforme se otorgaban las concesiones, sus pliegos particulares establecían el límite tarifario entre el 12 y el 15\% del capital (sin precisar el capital base para realizar el cálculo).

\footnotetext{
${ }^{1}$ La prohibición de aplicar los precios resultantes de la maximización del beneficio, imponiendo en su lugar otros que cubran costes, sigan la regla competitiva, etc. es un mecanismo clásico de regulación de cualquier empresa en competencia imperfecta con el fin de proteger a los consumidores.
} 
La Ley de 1855 introduce la posibilidad de disminución en tarifas: si la compañía no accedía a bajarlas el Gobierno lo haría de oficio con solo garantizar a la empresa "los productos totales" del último año más el aumento progresivo que hayan tenido por término medio en los últimos cinco años (pero no determina cómo calcularlos). El juego de las compañías, ante esto, fue no rebasar la tarifa máxima legal ${ }^{2}$ y no confesar apenas ganancias, así el tema de las tarifas quedó abierto sin encontrar jamás una solución la crisis de la primera guerra mundial.

En 1876 el segundo gobierno de Cánovas había nombrado una comisión para estudiar las tarifas vigentes y sus posibles reformas, afectada por circunstancias que entorpecieron su labor (incluyendo muertes de sus miembros) que impidió elaborar un informe. Aun así, con ese motivo, se realizó una importante encuesta entre las instituciones públicas de carácter económico en relación con el servicio ferroviario, que obtuvo como respuesta una serie de quejas sobre la complejidad tarifaria, falta de la publicidad necesaria sobre ellas y precios excesivos, pidiendo aplicación obligatoria de la tarifa más económica, unificación y revisión. ${ }^{3}$ La Junta de Cádiz llegó a proponer como solución la nacionalización de las compañías casi en condiciones de expropiación. Esta encuesta cayó en el olvido hasta junio de 1882, cuando tras nuevas protestas se reactiva en junio la comisión de tarifas, de cuyo dictamen salió la Orden de 1 de febrero de 1887 que legalizaba las prácticas tarifarias debatidas, exigiendo la aplicación de la más reducida posible, así como una adecuada publicidad. Esta fórmula no dio satisfacción a los usuarios, ya que las compañías se aprovecharon de lo que les resultaba favorable y eludieron lo que no les interesaba.

Como desde la década de 1880 el gobierno intentaba conseguir disminuciones tarifarias excepcionales, en 1888, con motivo de la crisis cerealista, proyectó la disminución en tarifas prevista en Ley si bien no aplicada, combinada con garantizar los beneficios del año anterior. Durante la depresión de los noventa, que unía a dicha crisis el cierre del mercado francés a la exportación de vinos nacionales, el nuevo planteamiento arancelario y la depreciación de la peseta, vuelve a plantearse el tema tarifario: las compañías prefirieron realizar la rebaja sin contrapartida antes de realizar un análisis contable mayor que la suave inspección gubernamental a la que estaban acostumbradas. Al prologarse la crisis se intentó además autorizar al gobierno a negociar con las compañías la disminución en tarifas para carbón y abonos a cambio de aumentos en las de gran velocidad y en viajeros (Proyecto de Ley de Auxilios de Ferrocarriles de 1892), lo que no convenció ni a las Cortes ni a las Compañías, si bien éstas en diciembre de 1893 aceptarían finalmente las rebajas. Para resolver la disparidad entre ambos proyectos se envía otro en junio de 1894, también rechazado.

En diciembre de 1900 al ministro de Agricultura le es encomendada la negociación de la revisión tarifaria, sin llegar a resultados y cinco años después, los buenos resultados que obtenían las compañías llevaron a que el gobierno, presionado por la opinión pública, siguiera solicitando las rebajas por lo que decidió convocar la Conferencia Ferroviaria en junio y noviembre, cuyas conclusiones deberían elevarse al gobierno con carácter no vinculante. El camino de los gobiernos se perfilaba en una sola dirección, la nacionalización y la intervención, y los resultados alcanzados por la Conferencia fueron nulos, con dictámenes ni siquiera sometidos a votación, limitándose a la publicación de una serie de textos contradictorios, sin éxito y cayendo el tema en saco roto hasta $1914 .^{4}$

\footnotetext{
${ }^{2}$ La tarifa máxima legal se calculaba sobre una base de percepción para todas las líneas por kilómetro recorrido y clase de viajero, número de animales o unidad de peso de las mercancías. Para calcularlas no se han encontrado huellas de aplicar criterios de ajuste a costes, subvenciones y otros factores, resultando así una maraña de tarifas, distintas en una misma compañía o iguales en tramos distintos sean de la misma compañía o no, de forma que la situación real no correspondió con los principios generales del régimen tarifario.

${ }^{3}$ Recibiendo cuarenta y una respuestas procedentes en su mayoría de las Juntas Provinciales de Agricultura, Industria y Comercio.

${ }^{4}$ La conferencia fue conocida especialmente por la obra que Eduardo Maristany presentó como respuesta: La conferencia ferroviaria de 1905.
} 
En 1914 y como afirma Artola, a la incapacidad para aumentar el tráfico se añade la subida del coste de la vida y del precio del carbón; las compañías se ven en la crisis más grave de su existencia al responsabilizárselas de la subida de precios de las subsistencias por no bajar las tarifas, argumento que no conseguían refutar, viendo aumentados a la vez sus costes de explotación terriblemente (Artola, 1978, p. 409). En la primera etapa de esta crisis, el Proyecto de Ley de Subsistencias intenta actuar sobre tarifas, pidiendo La Cierva en el Congreso una disminución (sin tener en cuenta el aumento en costes), completando su actuación con las Conferencias de 1915. En noviembre de 1916, con la nueva Ley de Subsistencias se dota al Gobierno de la facultad de imponer rebajas tarifarias a compañías subvencionadas que nunca se llevó a cabo.

La huelga de 1917 junto con el aumento en el precio del carbón y demás gastos llevaron a que las compañías, ahogadas mientras tanto por la realidad del incremento en costes existente, solicitasen aumento en tarifas, como se observa en el II Congreso de Economía Nacional, celebrado en 1917, concretamente en la ponencia de Garí Gimeno, Secretario de la Asociación del mercado libre de valores de Barcelona; resultado del Congreso fue la reunión de una Asamblea Nacional de Ferrocarriles en enero de 1918, donde Garí Gimeno apoyó nuevamente la necesidad de aumento tarifario, mientras el resto de peticiones estaban en el extremo opuesto. La Asamblea, con su incorrecto planteamiento de los problemas del momento, no tuvo influencia sobre el desarrollo de la crisis.

Llegamos así dos meses después al mandado de Francisco Cambó, quien contempló que el Estado había de mantener tarifas económicas y para ello deberían ser subvencionadas. Dicho mandato terminó el 6 de noviembre de 1918, año que se había iniciado en medio de la lucha de las compañías por el aumento de tarifas.

La parte más importante de su proyecto político quedó incompleta al no haberse discutido a nivel parlamentario. Pero ya estaba servida la semilla para que el tema levantase pasiones políticas, pues durante dicho mandato, el proyecto de Ley de Bases para la nacionalización de la propiedad de los ferrocarriles dio forma a un proyecto de Ley que autorizaba la subida tarifaria por encima del máximo legal. En el Real Decreto de 26 de diciembre de 1918 (llamado Decreto Cortina) su sucesor, José Gómez de Acebo, marqués de Cortina, aprueba un aumento del 15\% sobre la tarifa legal, que el Senado corrigió y materializó sobre tarifas vigentes. La respuesta de las compañías fue una petición de subida de un 35\% adicional en una exposición de 30 de noviembre de 1919 elevada al presidente del Consejo para evitar la quiebra; aunque al principio bien acogido por Fomento y aprobado por el Senado, La Cierva se opuso en las Cortes y no se llegó a ninguna decisión.

El 15 de abril de 1920 Ortuño elaboró unas Bases cuya aplicación hubiera llevado a un aumento en tarifas, pero no se aplicó. Las compañías pedían una revisión a fondo, manifestándose en febrero de 1921 a favor de precios adaptados a las necesidades y costo del servicio, coincidiendo con el asesinato de Dato y el nuevo mandato de La Cierva, quien en su Proyecto de Ley sobre Transportes crea el Consejo Superior de Ferrocarriles al que transfería las decisiones tarifarias. Ya hemos dicho que el Gobierno cae sin haberse puesto el Proyecto en marcha, entrando otro Gobierno Nacional presidido por Maura; en ese mandato sí que se creó por Real Decreto de 15 de marzo de 1922 el Consejo Superior Ferroviario, que propuso una subida de tarifas del $13,5 \%$, la cual el ministro rechazó reclamando una revisión diferencial que no dio tiempo a ponerse en vigor.

En septiembre de 1923 tras el golpe de estado de Miguel Primo de Rivera, el Consejo Superior de Ferrocarriles (nuevo nombre que da el Directorio Militar al proyectado Consejo Superior Ferroviario) ostentará la competencia para la determinación de las tarifas por el Estatuto Ferroviario de 1924; pero llegamos al final de periodo provisional del Estatuto sin haber solucionado el problema tarifario. Tras la caída de la dictadura, el gobierno de Dámaso Berenguer tampoco conseguirá resolver el tema, que llegará sin solución clara al gobierno de la Segunda República española.

5.2. Intervencionismo en costes. Las restricciones al libre empleo de factores productivos: el caso del carbón

El estudio del empleo del factor carbón es un parámetro muy útil a la hora de observar el camino de anti-libertad de mercado en España materializado en la industria ferroviaria. El carbón 
fue un factor productivo de vital importancia, puesto que era preciso no solo como combustible, sino también empleado por los hornos de fundición encargados de laminar carriles y accesorios de vía para el tendido de la red. En un principio, al permitir la Ley de 1855 la importación de hulla libre de derechos, la compra de carbones extranjeros, especialmente británicos, fue notable.

Con respecto a la compra de factores productivos, de 1875 a 1884 el consumo de combustible, además, presenta un fuerte crecimiento; de 1885 a 1894, si bien el consumo permanece estacionario, coincidiendo con la recesión general económica, las importaciones satisfacen más de la mitad de la demanda doméstica. Esta situación cambia a principios del nuevo siglo, produciéndose un fuerte aumento en consumo de carbón nacional tras la adopción de la política proteccionista de finales del siglo XIX, pero el carbón español era caro y de mala calidad, puesto que no se beneficiaba de las economías de escala ni fletes baratos del inglés; así, de 1895 a 1904 subió la producción de hulla nacional más que las importaciones, prologándose esta situación hasta 1913 (Gómez-Mendoza, 1982, pp. 157-160).

Al proceso de incorporación a la producción de hulla nacional habían contribuido por un lado el proteccionismo, la depreciación de la peseta y la construcción de líneas férreas carboneras que facilitaban el tráfico del mercado interior, y por otro la intención a la que aludíamos antes de que esta industria no fuese sensible a los peligros originados por problemas y conflictos externos. Esta situación supuso un aumento en costes para los consumidores de carbón, lo que sufrieron claramente las compañías ferroviarias, que acabarían adquiriendo minas en propiedad. Lógicamente estamos encontrando aquí una situación anómala en la minimización de costes implícita en cualquier proceso productivo: bien la restricción de emplear un combustible nacional más caro, bien el empleo del mismo siendo previamente producido por la misma empresa harían inaplicable el principio de la demanda general del carbón en el mercado de factores (que sería el ingreso marginal que reporta su productividad marginal).

\section{Los argumentos y el debate}

En este apartado analizaremos la tendencia general del pensamiento económico a través de las posiciones publicitadas en el contexto de la situación económica y financiera general; para ello distinguiremos por un lado los argumentos y por otro las propuestas.

\subsection{Argumentos para la intervención en el sector}

Antes de entrar a valorar los diferentes tipos de intervención pública en el sector de los ferrocarriles, conviene atender a una cuestión previa, que con frecuencia queda soslayada como irrelevante. Sin embargo, resulta tremendamente significativo examinar los motivos que se esgrimen para justificar dicha intervención, pues suelen aparecer yuxtapuestas argumentaciones de carácter independiente, y no siempre compatibles, que pueden predisponer hacia una forma determinada de solución.

- Existe una tendencia natural hacia el monopolio.

Un primer argumento esbozado para justificar la intervención pública en el sector es la tendencia connatural hacia el monopolio. Incluso se señalaba que en este mercado se daría una situación de doble monopolio, como ya se hacía constar en el Informe Subercase de 1844:

Decimos doble monopolio porque en efecto, tiene lugar bajo dos aspectos enteramente diversos, pero simultáneos; el primero porque destruye todos los demas medios de conducción que existian en la zona de terreno á donde alcanza la influencia del ferrocarril; y el segundo, porque después de atraidos á esta via todos los efectos trasportables los conduce por ella sin competidor de locomoción y sin mas freno en su exigencia que la tarifa estipulada.

En general, este tipo de denuncias del monopolio no revierten en una defensa del régimen de competencia, pues para el mercado del ferrocarril se concibe como ruinoso y anárquico, suponiendo un enorme dispendio de recursos y la más que probable quiebra para las compañías competidoras. El peligro del monopolio, sin embargo, estriba en que, si se le concede al explo- 
tador libertad de fijación de las tarifas, estas se situarían a un nivel muy elevado, proporcionando cuantiosos beneficios a costa de los clientes.

- Es un servicio público.

El segundo argumento muestra cierta relación con el anterior, pero mantiene una intensidad muy superior. Se trata de que, en cuanto a su función económica y social, las redes de transporte constituyen un auténtico "servicio público", por lo que su carácter es cualitativamente distinto de las actividades económicas privadas. La introducción de esta categoría tiene implicaciones muy considerables, tanto desde una perspectiva teórica como práctica, por cuanto supone contemplar un ámbito creciente de actuación al margen de los principios económicos generales. Como indicaba Blas Vives (1918m, p. 12):

Para la mayor parte de los problemas económicos, al Estado no se le podrá exigir otras medidas sino aquellas que faciliten el juego de las iniciativas particulares; pero en aquellos otros problemas a cuya solución están vinculados los supremos intereses patrios, la política debe ser más decidida, más directa, más completa, llegando a los remedios extremos que las circunstancias impongan.

En 1918, Pedro García Faria, ingeniero jefe de caminos, llegaba por esta vía aún más lejos, señalando que como los ferrocarriles "contribuyen en el más alto grado al fomento de la riqueza y progresos patrios, deben ser examinados al par y con igual criterio que los ramos de Guerra, Marina, Instrucción, Justicia, Correos, Seguridad y otros muchos imprescindibles en toda sociedad bien organizada y en los cuales no se pregunta siquiera si los gastos superan a los ingresos". 5

- Las empresas están controladas por oligarcas, o por extranjeros.

Desde una perspectiva complementaria a las anteriores, el que este servicio público se encontrara en manos privadas no constituiría el principal problema que afectaba a la situación de los ferrocarriles españoles, sino que se hallara bajo el control de oligarquías financieras, o sobre todo, de intereses extranjeros. Así lo ponía de manifiesto Eloy Luis André ante el II Congreso de Economía Nacional, denunciando al tiempo tanto el caciquismo local como el imperialismo financiero de países vecinos: "no puede haber una economía nacional allí donde los medios de circulación y de crédito están mediatizados por capitales exóticos o por intereses egoístas". 6

Pero sobre todo, y en correspondencia a la oleada nacionalista de la época, los principales objetivos de las denuncias eran los capitalistas extranjeros. Entre otros muchos testimonios, así lo señalaba en 1915 Juan de la Cierva (Vives, 1918, p. 12):

y es lo más triste que aconteciera ya entonces, y todavía no se haya remediado, que fueran los capitales extranjeros, las inteligencias extranjeras, las combinaciones financieras extranjeras las que en España, realmente, dieran comienzo a todas estas obras, porque ahora lo estamos pagando [...] que haya Comités en París y en Londres que entiendan de todas estas cosas que son nuestra propia entraña, que son nuestra sangre, sin las cuales no podemos vivir!

- Las empresas necesitan apoyo financiero público.

Existen, sin embargo, planteamientos un tanto distintos, y a menudo vinculados a la patronal del sector, que defienden la intervención pública, pero en defensa de las compañías. El motivo es que estos monopolistas, lejos de ostentar un poder omnímodo, serían en realidad "colosos de barro, funcionando como desquiciadas por la penuria, y arrastrando vida de empobrecimiento, y necesitadas de urgentes auxilios para no perecer en total miseria" (Sánchez de Toca, 1900, p. 2). El propio Sánchez de Toca indica que el interés de los pequeños ahorradores, propietarios de acciones de las empresas ferroviarias, ha de inspirar también a los poderes públicos en su regulación del sector.

Si es cierto que no deben admitirse beneficios extraordinarios, no lo es menos que el Estado, estableciendo las condiciones de actuación de las empresas, adquiere una especie de compromi-

\footnotetext{
${ }^{5}$ Asamblea Nacional de Ferrocarriles (1918, p. 290).

${ }^{6}$ II Congreso de Economía Nacional (1917, p. 408).
} 
so moral de garantizarles el beneficio mínimo normal en otras actividades económicas. De este modo, la situación financiera delicada en que se encontraban las empresas del sector no era culpa de una mala gestión, sino que se debía a las regulaciones públicas, sea directamente al fijar unas tarifas excesivamente bajas, sea indirectamente apoyando el consumo de carbón nacional, menos eficiente y más caro que el extranjero, por lo que el Estado habría de intervenir en auxilio de las compañías, en justa contraprestación al servicio que cumplen.

\subsection{Grandes propuestas de intervención}

Procederemos ahora a analizar las principales propuestas del periodo en torno a cómo debería intervenir el Estado en el sector. Obviando ahora planteamientos excesivamente específicos o casi anecdóticos, nos centraremos en tres grandes líneas, que en buena medida marcaron el camino hacia el monopolio estatal.

\section{- Nacionalización.}

De forma creciente, pero especialmente a partir de la Gran Guerra, se generalizaron las demandas de nacionalizar el sector. En ocasiones, se trataría de una medida meramente provisional, a modo de preparación de intervenciones más profundas; pero en otras, se consideraba como la verdadera solución a los problemas del ferrocarril en España.

Antes de entrar en otras consideraciones, el primer aspecto de interés es el de clarificar qué se entendía por nacionalización, término que no siempre tuvo una misma significación. En principio, se trataría de recuperar el carácter nacional del sector, rescatándolo de los intereses extranjeros presentes desde su más temprana implantación. En una versión más tibia, implicaría sólo que el control de las compañías ferroviarias quedara en manos de personas e instituciones del país. Desde otra perspectiva, supone que todo el capital de dichas empresas fuera español, para lo que se llegó a proponer que las acciones tuvieran un carácter nominativo, vigilando los poderes públicos que los financieros extranjeros no violaran este precepto mediante el uso de testaferros. Así, el antiguo ministro Fermín Calbetón planteaba en su ponencia presentada ante la Asamblea Nacional de Ferrocarriles de 1918 que:

El Gobierno exigirá la nacionalización de las Sociedades, una vez hecha la prórroga de sus concesiones; no permitirá que en sus Consejos ni en sus oficinas, ni en su servicio, figuren extranjeros sin su expresa aprobación, ni personajes decorativos. ${ }^{7}$

Más allá, en el mismo congreso, el catedrático de Economía José María Zumalacárregui defendía la nacionalización no sólo de la red ferroviaria, sino también de todo el material fijo y móvil a emplear en los ferrocarriles, por lo que el Estado debería procurar que todo el material se fabricara en España (Zumalacárregui, 1918, p. 243).

Este movimiento de nacionalización económica no se limitaba al sector del transporte, ni era específico de nuestro país. Ya desde las tensiones previas a la Guerra Mundial, pudo comprobarse que las relaciones económicas internacionales eran susceptibles de subordinarse a los intereses políticos y estratégicos. De este modo, cualquier injerencia de organismos públicos o privados extranjeros en la economía nacional era observada con suspicacia, especialmente en sectores como el que nos ocupa, cuya función logística e incluso directamente militar cobraba cada vez más importancia.

Poca resistencia pudo advertirse a esta corriente. En algún caso, no obstante, se advirtió de los costes y peligros de una política nacionalizadora. Por un lado, la sustitución de esos capitales extranjeros por los nacionales podía hipotecar el ahorro nacional, alejándolo de otros destinos más necesarios para el desarrollo integral de la economía. Por otro, no siempre la sustitución de materiales extranjeros por los producidos en el país era factible, o económicamente rentable. Es el caso del uso de carbón nacional, más caro y menos eficiente que el importado. Cabe entender desde una óptica política esa búsqueda de la independencia en los consumos energéticos, pero lo cierto es que su utilización suponía cargar al sector con unos costes suplementarios

\footnotetext{
${ }^{7}$ Asamblea Nacional de Ferrocarriles [1918], p. 115.
} 
muy elevados, que podrían transmitirse al resto de la economía. Por ello, no pocas voces entendían que "el verdadero auxilio para las Compañías ferroviarias, como para todo el país, sería una fuerte rebaja en el precio del carbón mineral" (André, 1918, p. 492). Finalmente, se señalaron las escasas que ventajas que traería rescatar el sector del capital extranjero para entregarlo a las oligarquías financieras patrias. Esa era la denuncia que Eloy Luis André efectuaba en 1918 respecto al programa de Cambó.

- Sindicación.

En relación con la tendencia anteriormente mencionada, pero con una relativa independencia, cabe señalar las propuestas de un tinte claramente corporativista. La solución a los problemas ferroviarios pasaría por la creación de organismos que aglutinaran a las empresas del sector, fueran llamados sindicatos, corporaciones o cárteles.

Aquí cabría diferenciar dos posibilidades: una agrupación meramente privada entre empresas, o un organismo semipúblico, con el Estado como socio principal. En el primer supuesto, las ventajas e inconvenientes se perciben claramente. Las empresas podían llegar a acuerdos en el seno del sindicato para racionalizar sus recursos, distribuyendo territorialmente sus ámbitos de actuación, coordinando sus tarifas de acuerdo a pautas comunes, etc. Pero es evidente que si tal procedimiento puede resolver los problemas financieros de las empresas, lo que realmente implica es el fin de toda posible competencia, reforzando la posición de dominio monopolístico del mercado.

Para eludir este peligro, a menudo estos planteamientos corporativistas pasaban por una intervención directa de los poderes públicos en los organismos sectoriales, contemplada en ocasiones como un preludio a una futura estatificación del ramo. Así, la Comisión Burgalesa de Iniciativas Ferroviarias declaraba en su ponencia al Congreso Nacional de Ingeniería de 1919 que:

Es, sin duda, el único procedimiento que consiente ligar de una manera más completa la iniciativa privada al Estado, interesando a los ciudadanos, individual y colectivamente, en un solo ideal, el del engrandecimiento de la Patria, permitiendo la acción armónica de las Corporaciones populares e industriales. ${ }^{8}$

No escasearon tampoco las críticas a esta idea, a menudo basadas en el clásico prejuicio contra la actividad industrial del Estado, como se decía en un artículo anónimo de 1923: "Si el Estado ha de estimarse de por sí mal industrial, será también un deplorable socio para fines de esta índole" (Anónimo, 1923, p. 39).

La presencia pública en este tipo de organismos, de por sí complejos al basarse en la toma de decisiones colectivas, podía propiciar su burocratización, ralentizando las intervenciones hasta el punto de perder su eficacia. En plena dictadura de Primo de Rivera, época dorada para experimentos de este tipo, se criticaba desde la Revista Nacional de Economía el funcionamiento de los Consejos de Economía Nacional, Superior Bancario y Superior Ferroviario, porque su acción era tan burocrática y tan lenta, que parecían inventados para dar cargos de relumbrón a infinidad de figuras decorativas.

- Estatificación.

La intervención más decidida y completa, por supuesto, era la absorción por parte del Estado de la gestión ferroviaria, que implicaba la reversión de las líneas, la cancelación de las concesiones que disfrutaban las empresas y la explotación directa por parte de organismos administrativos o empresas públicas. Si en la práctica supone la consolidación del monopolio y la eliminación de la competencia, la gestión pública evita los riesgos de incrementos desmesurados en las tarifas, dado que no se perseguiría la maximización de beneficios, atemperada por los condicionamientos de índole política.

Frente a lo que puede suponerse atendiendo a la historia reciente de RENFE, tardó mucho tiempo en consolidarse esta opción, muy posiblemente por la larga vigencia de los principios clásicos en torno a las funciones del Estado. Incluso Antonio Maura, quien ha sido considerado

\footnotetext{
${ }^{8}$ Congreso Nacional de Ingeniería (1919, p. 182).
} 
como uno de los paladines del nuevo intervencionismo conservador, se declaraba fiel a la ortodoxia clásica en la clausura del II Congreso de Economía Nacional:

[El Estado] necesita proceder con severísima cautela para no emprender por sí mismo otras directas actividades fabriles ni otras empresas económicas, sino las que estrictamente le están reservadas, y son únicamente aquellas que jamás se pueden obtener de la industria privada ni siquiera aguijándola y auxiliándola. ${ }^{9}$

Así, el resultado más frecuente durante la oleada nacionalista coetánea a la Gran Guerra era ambivalente: la estatificación era el sistema óptimo para resolver los problemas ferroviarios en España, pero las circunstancias aconsejaban demorar su implantación hasta un futuro incierto. Esta era la conclusión mayoritaria en la Asamblea Nacional de Ferrocarriles de 1918, en la que no obstante se escucharon voces minoritarias tanto en contra de la estatificación como defendiendo su implantación inmediata.

Conocidas eran las razones que frenaban la reversión estatal de las líneas, y que no sólo tenían un carácter coyuntural sino que guardaban relación con la propia estructura del Estado:

Ha de suponerse desde luego descartado el principio de estatificar en España la explotación de los ferrocarriles, por las dificultades financieras que para el Tesoro público llevaría consigo esta radical innovación y por la falta de preparación de los organismos oficiales que habrían de tomar a su cargo este importantísimo servicio.

En la línea cuasi-regeneracionista que inspiraba la Revista de Economía Nacional, esta vinculación entre reformas económicas y reformas políticas era muy clara. Así lo señalaba su director, Emilio Riu en 1918 (Riu, 1918, p. 12):

Lanzarse a los grandes gastos que ocasionaría una obra de estatificación de grandes obras públicas con un Estado y una Administración pública que no sabe ni recaudar los impuestos ni fiscalizar los gastos, y con instrumentos parlamentarios tan eficaces que en veinte años ni una sola vez han examinado las Cuentas Generales del Estado es pura y simplemente querer deslumbrar al país con una obra más brillante que sólida, obra que, de aprobarse, sería la ruina de la Hacienda y la consagración del atraso industrial durante otra generación. Para lanzarse a una gran obra de estatificación hay que tener primero un Estado, una moral administrativa superior a la actual y mayor capacidad técnica.

De todos los argumentos mencionados, es posible extraer algunas pautas. En primer lugar, puede percibirse una clara evolución de los planteamientos en torno al sector de los ferrocarriles en un sentido más intervencionista. La actuación del Estado es necesaria para solventar los problemas ocasionados por esa concurrencia entre un mercado de monopolio y un servicio público de trascendencia para el desarrollo económico nacional. No es, por supuesto, el único campo en el que se produce esta evolución teórica, de tal forma que el sector es sólo la punta de lanza de una nueva política económica general.

Sin embargo, para la implementación de esta política económica se precisa una completa reestructuración del organismo estatal, tanto en su vertiente administrativa como en la financiera, creando fuentes de ingresos que permitan afrontar las nuevas y crecientes funciones a asumir.

Por reseñar una anécdota que no deja de resultar enormemente significativa, recordamos que entre 1917 y 1918 el ministro Santiago Alba llevó a las Cortes dos proyectos que suscitaron un enorme debate: la creación de un impuesto sobre los beneficios extraordinarios obtenidos merced a la Guerra Mundial, y una ley de apoyo a la industria naciente. La primera propuesta se rechazó, mientras que la segunda fue aprobada con rotundidad. Los efectos de esa nueva política de ayudas directas a la industria fueron prácticamente nulos, en consonancia con la carencia de recursos financieros disponibles. Por tanto, la vinculación entre políticas económicas y el marco presupuestario en el que se basan es inmediata, máxime tratándose de proyectos de im-

\footnotetext{
${ }^{9}$ II Congreso de Economía Nacional (1917, p. 670).
} 
portancia cuantitativa tan colosal como la propiedad y gestión de la totalidad de los ferrocarriles españoles.

\section{Conclusiones}

El intervencionismo español acabó por crear tal poder al Estado que desembocó en una amplísima política estatificadora. A la retórica anti-competencia le siguió la práctica en el mundo real, las reacciones empresariales se adaptaron a esta situación, se acentuaron el corporativismo, las cartelizaciones, acuerdos tipo trust y la sed por el poder del monopolio, y el empresario se acostumbró a alejarse del mercado competitivo y a no preocuparse por la competitividad ni los costes (Velarde, 2001, pp. 898-899).

Puede observarse un camino claro desde finales del siglo XIX y hasta la culminación en el corporativismo de la dictadura de Primo de Rivera: el proteccionismo español, unido a las ideas nacionalizadoras, fue un campo de cultivo para que el ferrocarril se configurase desde sus primeros momentos como una industria estratégica protagonista de los argumentos españoles de factura regeneracionista en contra de la competencia y a favor del fomento y la intervención pública, y a su vez uno de los vehículos conductores de la defensa del corporativismo y el monopolio de Estado

Lo que parece un camino unidireccional e irreversible y que en el caso que analizamos, el ferrocarril, es el monopolio estatal en el que desembocó en 1941, es, sin embargo, resultado de criterios económicos y también políticos. En este sentido, podemos marcar una fecha clave: la primera guerra mundial. Durante este tiempo, la protección al ferrocarril no solo vendría marcada por la conocida secuencia proteccionismo-nacionalización-estatificación, sino que hay que tener en cuenta un claro criterio de prudencia añadido, que no es otro sino los peligros de los que se habría de proteger a la industria doméstica: por conflictos en el sector exterior, por la existencia de capitalistas extranjeros, por la posibilidad de quiebras en abastecimientos (como el caso del carbón); luego en ese caso, la opción proteccionismo-nacionalización puede considerarse además un mecanismo político de defensa y prevención en esta industria, creadora de riqueza y de vital importancia para la nación, vehículo de pasajeros en tiempos de paz y de tropas en tiempos de guerra.

Pero las ideas estatificadoras de la época analizada no tienen por qué considerarse implícitas en el espíritu que subyacerá años después en RENFE, monopolio estatal creado en la nueva España de la dictadura franquista, y que ostentará la propiedad absoluta de una industria estratégica, el ferrocarril, que reunirá junto a sus características de fuente de riqueza nacional, servicio público, tendencia natural al monopolio y necesidad de financiación estatal, unos fuertes intereses militares.

Nuestra opinión es que verdaderamente el ferrocarril fue un elemento indispensable en la retórica anti-competencia presente en la consolidación de la vía nacionalista del capitalismo español, pero hay dos secuencias distintas: por un lado un primer camino, al que hemos dedicado este trabajo, y que culmina con la Dictadura de Primo de Rivera y por otro lado la creación de RENFE, monopolio estatal gestado con unos fines propios por parte del franquismo y cuyas peculiaridades retóricas son objeto de otro estudio.

\section{Bibliografía}

Almenar Palau, Salvador. 2000. Álbum. En Enrique Fuentes Quintana (dir.): Economía y economistas españoles. Barcelona, Galaxia Gütenberg, tomo 4.

André, Eloy Luis. 1918. Problemas más vitales de nuestra política ferroviaria. Revista Nacional de Economía, tomo I (10), 473-492.

Anónimo. 1918. El problema de los ferrocarriles. Revista de Economía y Hacienda. Madrid, 29 de junio de 1918, 539-540.

- 1923. El problema ferroviario. Madrid, Samarán y Compañía.

Artiñano, Gervasio de. 1921. La explotación comercial. Tarifas. Nuestro problema general ferroviario. En Conferencias de carácter industrial y financiero, organizadas por el Instituto católico de Artes e Industrias. Madrid, Sucesores de Rivadeneyra. 
Artola Gallego, Miguel. 1978. La acción del Estado en Miguel Artola Gallego (dir.). 1978. Los Ferrocarriles en España. 1844-1943. Madrid, Servicio de Estudios del Banco de España, 359-453.

Asamblea Nacional De Ferrocarriles. 1918. Resumen de los Trabajos de la Asamblea. Madrid, V. Rico.

Calvo Sotelo, José. [1974 (1931)]. Mis servicios al Estado. Madrid, Instituto de Estudios de Administración Local.

Carreras, Albert. 1999. Los ferrocarriles en Europa: algunas perspectivas históricas. En Miguel Muñoz Rubio; Jesús Sanz Fernandez y Javier Vidal Olivares (eds.): Siglo y medio del ferrocarril en España 1848-1998. Economía, Industria y Sociedad. Madrid, Fundación de los Ferrocarriles Españoles, 33-54.

Cambó Batlle, Francisco. 1921. Elementos para el estudio del problema ferroviario en España. Madrid, Ministerio de Fomento, 6 vols.

Coll Martín, Sebastián y Sudriá i Triay, Carles. 1987. El carbón en España, 1770-1961: una historia económica. Madrid, Turner.

Congreso de Diputados. 1917-1921. Diarios de las Sesiones de Cortes. Archivo de las Cortes, Madrid.

II Congreso de Economía Nacional. 1917. Resumen de los Trabajos del Congreso. Madrid, V. Rico.

I Congreso Nacional de Ingeniería. 1920. Trabajos del Congreso. Madrid, Sucesores de Rivadeneyra.

Fraile Balbín, Pedro. 1998. La retórica contra la competencia en España. 1875-1975. Madrid, Fundación Argentaria.

García Delgado, José Luis y Roldán, Santiago. 1973. La formación de la sociedad capitalista en España 1914-1920. Madrid, Confederación española de Cajas de Ahorro.

Giuntini, Andrea. 1999. El ferrocarril italiano, de sus orígenes a hoy. En Miguel Muñoz Rubio; Jesús Sanz Fernández y Javier Vidal Olivares (eds.). Siglo y medio del ferrocarril en España 1848-1998. Economía, Industria y Sociedad. Madrid, Fundación de los Ferrocarriles Españoles. 81-104.

Gómez Mendoza, Antonio. 1982. Ferrocarriles y cambio económico en España. 1855-1913. Madrid, Alianza Universidad.

Gourvish, Terry. 1999. Los ferrocarriles como medio de transporte en Gran Bretaña. En Muñoz Rubio, Miguel; Sanz Fernández, Jesús y Vidal Olivares, Javier (eds.). Siglo y medio del ferrocarril en España 1848-1998. Economía, Industria y Sociedad. Madrid, Fundación de los Ferrocarriles Españoles, 55-64.

Izquierdo, Rafael. 2000. Cambó y su visión de la política ferroviaria: el inicio de un cambio. Madrid, Fundación de Ferrocarriles Españoles/Colegio de Ingenieros de Caminos, Canales y Puertos

Jiménez Ontiveros, Francisco. 1924. Bases para la resolución del problema ferroviario en España. Madrid, Imprenta de la Ciudad Lineal.

La Cierva, Juan de. 1915. Conferencias dadas en el círculo de la Unión Mercantil del 9 y 27 de febrero de 1915, Madrid, s.i.

Malo Guillén, José Luis. 2001. El pensamiento económico del krausismo español. En Enrique Fuentes Quintana (dir.): Economía y economistas españoles. Barcelona, Galaxia Gütenberg. 389-450, tomo 5.

Maristany, Eduardo. 1905. La conferencia Ferroviaria de 1905. Barcelona, Imprenta de Henrich y Comp. en comandita.

Martínez Vara, Tomás. 2006. Salarios y Programas de Bienestar Industrial en la empresa ferroviaria MZA (1915-1935). Investigaciones de Historia Económica (4), 101-138.

Merger, Michèle. 1999. Los ferrocarriles franceses desde sus orígenes a nuestros días: Evolución del marco jurídico e institucional. En Miguel Muñoz Rubio; Jesús Sanz Fernández y Javier Vidal Olivares (eds.). Siglo y medio del ferrocarril en España 1848-1998. Economía, Industria y Sociedad. Madrid. Fundación de los Ferrocarriles Españoles. 65-80. 
Ortúñez Goicolea, Pedro Pablo. 1999. La configuración de la red nacional y las grandes compañías ferroviarias: Norte y MZA, 1913-1936. En Miguel Muñoz Rubio; Jesús Sanz Fernández y Javier Vidal Olivares (eds.). Siglo y medio del ferrocarril en España 1848-1998. Economía, Industria y Sociedad. Madrid, Fundación de los Ferrocarriles Españoles, 273-298.

- 1992. Maura, Cambó y La Cierva ante el problema ferroviario. En Anales de estudios económicos y empresariales (7), 307-320.

- 2008. Cambio político, instituciones y empresas ferroviarias en España (1918-1936). En Investigaciones de Historia Económica: revista de la Asociación Española de Historia Económica (12), 141-170.

Porter, Glenn. 1999. Los ferrocarriles en los Estados Unidos: Mitos y Realidades. En Miguel Muñoz Rubio; Jesús Sanz Fernández y Javier Vidal Olivares (eds.). Siglo y medio del ferrocarril en España 1848-1998. Economía, Industria y Sociedad. Madrid, Fundación de los Ferrocarriles Españoles, 105-114.

Riu, Emilio. 1918. Introducción. Revista Nacional de Economía. Tomo I (10), 3-22.

Sánchez Hormigo, Alfonso y Malo Guillén, José Luis. 2001. Álbum. En Enrique Fuentes Quintana (dir.): Economía y economistas españoles. Barcelona, Galaxia Gütenberg, tomo 5.

Sánchez de Toca, Joaquín. 1900. Los caminos de hierro y el Gobierno. Revista de Obras Públicas. Tomo I, 371-376.

Serrano Sanz, José María. 2001. Economía y controversias de política económica a finales del XIX. En Enrique Fuentes Quintana (dir.). Economía y economistas españoles. Barcelona, Galaxia Gütenberg. Tomo 5, 155-196.

Tedde de Lorca, Pedro. 1978. Las compañías ferroviarias en España, 1855-1935, en Miguel Artola (dir.). 1978. Los Ferrocarriles en España. 1844-1943. Madrid, Servicio de Estudios del Banco de España, 2 vols. 9-354.

- 1996. La expansión de las grandes compañías ferroviarias españolas: Norte, MZA y Andaluces (1865-1930), en Pablo Martín Aceña y Francisco Comín Comín (coords). La empresa en la historia de España. Madrid, Civitas, 265-284.

Tortella Casares, Gabriel. 1973. Los orígenes del capitalismo en España: Banca, Industria y Ferrocarriles en el siglo XIX. Madrid, Tecnos.

Varela Parache, Manuel. 2000. Enseñanza y aplicación de la ciencia económica: el profesor Zumalacárregui. En Enrique Fuentes Quintana (dir.): Economía y economistas españoles. Barcelona, Galaxia Gütenberg, tomo 6, 319-344.

Velarde Fuertes, Juan. 1973. Política económica de la dictadura. Madrid, Biblioteca Universitaria Guadiana.

Vives, Blas. 1918. El problema de la red actual. En El Debate. Madrid, V. Rico, 11-15.

Waiss, Francisco. 1974. Historia de los Ferrocarriles Españoles. Madrid, Editora Nacional. 